\title{
Evaluation of right and left ventricular function in hard metal workers
}

\author{
S F HOROWITZ, A FISCHBEIN, D MATZA, J N RIZZO, A STERN, J MACHAC, \\ S J SOLOMON
}

\begin{abstract}
From the Division of Cardiology, Division of Environmental and Occupational Medicine, and Department of Biomathematical Sciences, The Mount Sinai School of Medicine, New York, NY, USA
\end{abstract}

\begin{abstract}
Ingested cobalt has previously been associated with the development of a congestive cardiomyopathy. Despite occasional reports of cardiomyopathy after industrial exposure to cobalt, this association remains controversial. In a study of $\mathbf{3 0}$ cemented tungsten carbide workers with a mean duration of exposure to cobalt of $9.9 \pm 5.3$ years radionuclide ventriculography was performed to study right and left ventricular ejection fractions at rest and exercise. For the entire group, rest and exercise biventricular function was normal. There was, however, a weak but significant inverse correlation between duration of exposure and resting left ventricular function $(\mathrm{r}=-0.40, \mathrm{p}<0.03)$. Workers with abnormal chest $x$ ray findings $(9 / 30)$ had relatively lower exercise right ventricular ejection fractions $(45 \% \pm 6 v 52 \% \pm 7, \mathrm{p}<0.02)$. An inverse relation was also found between rest and exercise right ventricular ejection fraction and severity of parenchymal abnormalities on $x$ ray examination $(r=-0.44, p<0.01$ and $r=-0.41, p<0.02)$. Diminished right ventricular reserve was probably due to fibrotic lung disease and early cor pulmonale. Although overt left ventricular dysfunction was not present, prolonged exposure to industrial cobalt may be a weak cardiomyopathic agent with unknown long term significance.
\end{abstract}

Coblt is widely used together with tungsten carbide in the manufacture of hard metal alloys. These alloys are used in the production of high strength, heat resistant cutting and drilling tools. Cobalt has long been considered the principal aetiological factor in the genesis of "hard metal disease," a pneumoconiosis occurring among workers in the cemented tungsten carbide industry. "Beer drinkers' cardiomyopathy" has also been well described as a distinct entity caused by the ingestion of cobalt salts added to beer as a foam stabiliser. ${ }^{1-3}$

Only rare case reports have implicated industrial exposure to cobalt as a cause of clinical cardiomyopathy. ${ }^{4}$ It is uncertain whether these isolated reports represent the chance occurrence of an idiopathic congestive cardiomyopathy in workers exposed to cobalt or whether occupational exposure was a contributing factor. There is evidence that systemic cobalt absorption occurs through the lungs'; however, no study has, to our knowledge, directly examined whether long term industrial exposure to cobalt may also be associated with cardiomyopathy.

The present study was designed to evaluate left and right ventricular function in a group of hard metal Accepted 14 September 1987 workers with a history of prolonged employment in the cemented tungsten carbide industry.

\section{Methods}

PATIENT POPUlation

A total of 30 hard metal workers, all formerly employed in hard metal processing plants, underwent rest and exercise gated blood pool imaging. This examination was part of a detailed cardiopulmonary evaluation of a group of 41 workers who underwent a wide range of clinical and laboratory tests, the results of which will be presented elsewhere (A Fischbein et al in preparation). The mean age for the 21 men and nine women was $41 \pm 9$ years (men $40 \pm 9$, women $42 \pm 9$ ). These individuals were exposed to cobalt for $10 \pm 5$ years (men $10 \pm 6$, women $8 \pm 4$ ). Ten of the men had smoked for an average of $23 \pm 12$ years whereas six of the women smoked for an average of $22 \pm 10$ years. The 16 smokers, as a group, smoked for an average of $23 \pm 11$ years. These differences may be explained on the basis of random variation.

RADIOGRAPHY

Standard posteroanterior chest $x$ ray films were 
obtained and interpreted according to the International Labour Office Classification of Radiographs of Pneumoconioses, $1980 .^{6}$ This classification is used for the standardisation of $x$ ray findings consistent with pneumoconiosis and graded on a 12 point scale. Within the abnormal group the degree of severity of the radiographic findings was considered for each subject as a continuous variable by summing the number of parenchymal zones scored as abnormal. Chest $x$ ray films were read and scored by experienced readers who were unaware of the cardiac imaging data.

\section{ELECTROCARDIOGRAPHY}

Standard 12 lead electrocardiograms were obtained and separately analysed without knowledge of other clinical or laboratory data. For comparison with cardiac imaging data, electrocardiograms were classified as normal or abnormal.

\section{RADIONUCLIDE VENTRICULOGRAPHY}

Gated cardiac blood pool imaging was performed at rest and with graded supine bicycle exercise. In vivo labelling of red blood cells was performed with 25$29 \mathrm{mCi}$ of ${ }^{99 \mathrm{~m}} \mathrm{Tc}$ stannous pyrophosphate. Data were acquired with a single crystal gamma camera and dedicated microprocessor (Technicare, series 120 and 450) using a general all purpose collimater. Each exercise period was three minutes in duration, with a 25 watt increment in resistance with each stage.

Left and right ventricular ejection fractions were generated from the best septal left anterior oblique view using a semiquantitative counts-based method (Technicare, QMICA) after background subtraction. Atrial separation was established by initial viewing of the cine ventriculogram. Data processing was performed by an experienced nuclear cardiology physician without knowledge of other clinical or laboratory data.

\section{Statistical methods}

The data were analysed using non-parametric, distribution free statistical techniques. Spearman correlations were computed for right and left ventricular ejection fractions (both at rest and with exercise), severity of chest $x$ ray findings, and duration of exposure to cobalt. Subjects were subdivided by $x$ ray findings and smoking history in order to explore group differences in cardiac function. Wilcoxon two sample tests were used to compare heart rate, systolic blood pressure, ventricular function, age, and duration of exposure to cobalt for each grouping.

\section{Results}

For the group as a whole, overall left and right
Table 1 Subclassification on the basis of electrocardiographic results for selected cardiac function tests

\begin{tabular}{|c|c|c|c|}
\hline \multirow[b]{2}{*}{ Variable } & \multicolumn{3}{|c|}{ Electrocardiogram } \\
\hline & Normal & Abnormal & p Value \\
\hline $\begin{array}{l}\text { No of subjects } \\
\text { Age (y) } \\
\text { Resting heart rate (beats/min) } \\
\text { Exercise heart rate (beats/min) } \\
\text { Resting systolic blood pressure }\end{array}$ & $\begin{array}{r}16 \\
42 \pm 8 \\
74 \pm 11 \\
133 \pm 18\end{array}$ & $\begin{aligned} 14 & \\
39 & \pm 10 \\
78 & \pm 9 \\
132 & \pm 19\end{aligned}$ & $\begin{array}{l}\overline{\text { NS }} \\
\text { NS } \\
\text { NS }\end{array}$ \\
\hline $\begin{array}{l}(\mathrm{mm} \mathrm{Hg}) \\
\text { Exercise systolic blood pressure } \\
(\mathrm{mm} \mathrm{Hg})\end{array}$ & $\begin{array}{l}121 \pm 13 \\
171 \pm 27\end{array}$ & $\begin{array}{l}119 \pm 15 \\
172 \pm 22\end{array}$ & NS \\
\hline $\begin{array}{l}\text { Resting right ventricular } \\
\text { EF (\%) } \\
\text { Exercise right ventricular }\end{array}$ & $40 \pm 5$ & $42 \pm 5$ & NS \\
\hline $\begin{array}{l}\text { EF }(\%) \dagger \\
\text { Resting left ventricular EF (\%) } \\
\text { Exercise left ventricular EF (\%) } \\
\text { Maximal work load (watts) }\end{array}$ & $\begin{array}{l}49 \pm 8 \\
54 \pm 7 \\
64 \pm 7 \\
90 \pm 33\end{array}$ & $\begin{array}{l}50 \pm 5 \\
52 \pm 6 \\
60 \pm 7 \\
95 \pm 22\end{array}$ & $\begin{array}{l}\text { NS } \\
\text { NS } \\
\text { NS } \\
\text { NS }\end{array}$ \\
\hline
\end{tabular}

EF = Ejection fraction.

Normal $\geqslant 37 \%$; tnormal $\geqslant 5 \%$ above rest EF; tnormal $\geqslant 45 \%$; §normal $\geqslant 5 \%$ above rest EF. It should be noted that age was not significantly related to any of the above cardiac functions.

ventricular ejection fractions were within normal limits (table 1). When the subjects were subdivided on the basis of chest $x$ ray findings, however, individuals with abnormal radiographs had significantly lower right ventricular ejection fractions with exercise $(s=114.5, p<0.02)$; no difference was found in left ventricular function (table 2 ).

In addition, a significant inverse relation was found between rest and exercise right ventricular ejection fractions and the degree of chest radiographic parenchymal abnormalities $(r=-0.44, p<0.01$, and $r=-0.41, p<0.02$, respectively)

A similar weak but significant inverse correlation was found between the duration of employment and the left ventricular ejection fraction at rest

Table 2 Subclassification on the basis of radiographic results for selected cardiac function tests

\begin{tabular}{|c|c|c|c|}
\hline \multirow[b]{2}{*}{ Variable } & \multicolumn{3}{|c|}{ Chest $x$ ray finding } \\
\hline & Normal & Abnormal & p Vabe \\
\hline $\begin{array}{l}\text { No of subjects } \\
\text { Age (y) } \\
\text { Resting heart rate (beats/min) } \\
\text { Exercise heart rate (beats/min) } \\
\text { Resting systolic blood pressure } \\
\text { (mm Hg) } \\
\text { Exercise systolic blood pressure } \\
\quad \text { (mm Hg) } \\
\text { Resting right ventricular } \\
\text { EF (\%) } \\
\text { Exercise right ventricular } \\
\text { EF (\%)† } \\
\text { Resting left ventricular EF (\%) } \\
\text { Exercise left ventricular EF (\%) } \\
\text { Maximal work load (watts) }\end{array}$ & $\begin{aligned} 19 & \\
38 & \pm 7 \\
76 & \pm 10 \\
134 & \pm 17 \\
121 & \pm 14 \\
171 & \pm 23 \\
42 & \pm 5 \\
52 & \pm 7 \\
54 & \pm 7 \\
63 & \pm 8 \\
93 & \pm 28\end{aligned}$ & $\begin{array}{l}11 \\
46 \pm 11 \\
75 \pm 12 \\
130 \pm 20 \\
120 \pm 13 \\
172 \pm 30 \\
39 \pm 6 \\
45 \pm 6 \\
54 \pm 6 \\
61 \pm 6 \\
91 \pm 32\end{array}$ & $\begin{array}{l}\text { NS } \\
\text { NS } \\
<0-027 \\
\text { NS } \\
\text { NS } \\
\text { NS }\end{array}$ \\
\hline
\end{tabular}


$(r=-0.40, p<0.03)$. No significant differences were found in right or left ventricular function with respect to age and smoking status.

There were 14 abnormal electrocardigrams among the 30 subjects. Axis deviation was the most common abnormality, with four right and three left axis deviations. Four had non-specific $S-T$ and $T$ wave abnormalities and three had incomplete interventricular conduction abnormalities. One had left ventricular hypertrophy and one had inferior wall $Q$ waves that were suggestive but not diagnostic of infarction.

When subjects with normal electrocardiograms were compared with those with abnormal tracings, no differences were observed for rest and exercise heart rates, right and left ventricular ejection fractions, systolic blood pressures, and workloads (table 1).

A history of dyspnoea on exertion was elicited from 26 of the 30 subjects examined. Thus caution must be exercised in the interpretation of results based on a comparison between symptomatic and asymptomatic individuals. Nevertheless, lower exercise heart rates $(s=98.0, p<0.03)$ and exercise systolic blood pressures $(s=103.5, p<0.01)$ were found in the subjects with dyspnoea on exertion. Workloads were also lower among the symptomatic workers but the difference did not reach statistical significance.

\section{Discussion}

In 1966 Kesteloot et al described a distinct and particularly severe form of congestive cardiomyopathy occurring in heavy beer drinkers in Belgium. ${ }^{1}$ A similar epidemic occurred shortly thereafter in Quebec, Canada, and Omaha, Nebraska, within one year of introducing cobalt salts as a foam stabiliser for a local beer. ${ }^{23}$ Although evidence for cobalt as the aetiological agent was initially circumstantial, no new cases appeared within one month of removing the cobalt as a beer additive. Cobalt was ultimately found in the ventricles of subjects with cardiomyopathy at ten times the normal control level. ${ }^{7}$

This beer drinkers' cardiomyopathy carried a high mortality and often presented with a fulminant, downhill course. ${ }^{8}$ Common clinical manifestations included large pericardial effusion, low cardiac output, increased venous pressure, and normal or high red cell counts. ${ }^{23}$ Pathologically, these patients had myocardial hypertrophy, slight chamber dilatation, and additional non-specific findings consistent with a noninflammatory cardiomyopathy. ${ }^{9}$

Average beer consumption among these patients exceeded a remarkable two dozen pints a day. The total daily cobalt load, however, still remained far lower than the daily intake for anaemic patients receiving cobalt as a haematinic. ${ }^{810}$ This suggested that other factors, such as alcohol intake or nutritional deficiencies, may be required as cofactor(s) for the development of clinically important cardiotoxicity.

On a biochemical level, the ability of the cobalt ion to complex with biologically important compounds may relate to its potential cardiotoxicity. Amino acids, adenine, glutathione, and lipoic acid can form cobalt complexes, some of which may be irreversibly stable. ${ }^{11-15}$

Cobalt is widely used in the hard metal industry for the manufacture of alloys of great stength and heat resistance. It is estimated that in the United States about 30000 workers may be at risk from exposure to cobalt in the tungsten carbide industry. Although acute cardiotoxicity from this type of exposure to cobalt appears to be rare, long term cardiac effects have not been well studied. A report by Barborik and Dusek in 1972 suggests that cobalt may be deposited in the myocardium after industrial exposure alone. ${ }^{4}$ Necropsy analysis of a hard metal worker who died in congestive heart failure showed myocardial cobalt levels exceeding those recorded in patients dying of beer drinkers' cardiomyopathy. ${ }^{4}$ In the present study, despite prolonged occupational exposure to cobalt, laboratory evidence of an occult cardiomyopathy manifested by overt left ventricular systolic dysfunction-that is, an ejection fraction below normal levels-was not found. A weak inverse correlation, however, was found between resting left ventricular ejection fraction and duration of exposure to cobalt. This may be significant because the resting ejection fraction does not normally decline with age alone. ${ }^{16}$ Whether this represents a subtle, cumulative myocardial effect of cobalt remains to be determined.

In beer drinkers' cardiomyopathy two or three cofactors may have been responsible for the early fulminant cardiotoxic manifestation of cobalt. It is possible that myocardial deposition of cobalt is relatively widespread among hard metal workers but not associated with a clinically important cardiomyopathy in the absence of other cofactors. It is also possible that hard metal workers develop heart failure more readily than other subjects when challenged with coronary artery disease, hypertension, valvular heart disease, viral infections, and alcohol. Evidence exists, for instance, that cigarette smoking is a risk factor for the development of myocardial dysfunction independent of coronary artery disease. ${ }^{17}$ The identification of occupational exposure to cobalt as a cofactor for the development of cardiomyopathy can only be achieved by extensive, non-invasive screening and long term follow up of a larger population of hard metal workers.

In the current study the presence of an abnormal chest $x$ ray film was associated with evidence of less vigorous right ventricular function. The findings in the 
present study probably represent occult or early cor pulmonale related to hard metal pneumoconiosis. Altered right ventricular systolic function has been shown to be a marker of pulmonary arterial hypertension. An abnormal exercise response of the right ventricle also occurs with pulmonary hypertension, as has been previously shown in chronic obstructive lung disease and mitral stenosis. ${ }^{18-20}$ The presence of interstitial lung fibrosis in hard metal workers and secondary heart failure has been known for more than two decades. ${ }^{21}$

Alterations in ventricular diastolic compliance was not evaluated in the present study, since the traditional criteria for diagnosis of cardiomyopathy is systolic dysfunction. Recent evidence, however, suggests that diastolic dysfunction may occur as an early manifestation of cardiomyopathy ${ }^{22}$ whereas systolic function remains normal or near normal. Diastolic dysfunction may be an alternative explanation for symptoms of shortness of breath, decreased exercise duration, and right ventricular dysfunction secondary to pulmonary hypertension. Interestingly, in the dog intravenous cobalt produced evidence of raised left ventricular end diastolic pressure associated with normal to increased left ventricular ejection fractions. ${ }^{24}$ Right ventricular volumes were increased, although left ventricular systolic volumes were decreased along with the enhanced ejection fraction. These findings strongly suggest that increased left ventricular compliance was the cause of the haemodynamic abnormalities associated with ultrastructural changes consistent with an early cardiomyopathy.

\section{Conclusion}

In a group of tungsten carbide workers there was no clear evidence of overt systolic left ventricular dysfunction despite prolonged occupational exposure to cobalt. Nevertheless, a subtle but significant inverse relation between left ventricular function and duration of exposure was found within the normal ejection fraction range, suggesting that industrial exposure to cobalt is a possible cofactor or weak aetiological agent in the genesis of myocardial dysfunction. The finding of relatively diminished right ventricular contractility as a function of radiographic pulmonary involvement suggests that occult cor pulmonale occurs with some frequency among tungsten carbide workers. Abnormal left ventricular compliance occurring as an early manifestation of a cardiomyopathy could explain some of the findings in the present study and has not been excluded. Further work is required to understand more fully the nature and long term significance of the cardiac effects of prolonged industrial exposure to cobalt. Whether clinically important cardiomyopathy or cor pulmonale ultimately develops at a higher rate among tungsten carbide workers with cobalt serving as a factor (or cofactor) remains to be determined.

These data have been partially published in abstract form for the International Conference on Heavy Metals, Athens, Greece, 10-13 September 1985, and the World Congress of Cardiology, Washington, DC, 9-13 September 1986.

Supported in part by Bernard and Josephine Chaus through the Heart Research Foundation and by the National Institute of Environmental Health Sciences, Center Grant, ES 00928.

Requests for reprints to: Dr S F Horowitz, Mount Sinai Medical Center, One Gustave L Levy Place, New York, NY 10029.

\section{References}

1 Kesteloot H, Terryn R, Bosmans P, Joossens JV. Alcoholic perimyocardiopathy. Acta Cardiol (Brux) 1966;21:341-57.

2 Kesteloot H, Roelandt J, Willems J, Claes JH, Joossens JV. An enquiry into the role of cobalt in the heart disease of chronic beer drinkers. Circulation 1968;27:854-63.

3 McDermott PH, Delaney RL, Egan JD, Sullivan JF. Myocardosis and cardiac failure in men. JAMA 1966;198:253-6.

4 Barborik M, Dusek J. Cardiomyopathy accompanying industrial cobalt exposure. Br Heart $J$ 1972;34:113-6.

5 Schepers GWH. The biological action of tungsten carbide and cobalt. AMA Arch Ind Heath 1955;12:140-6.

6 International Labour Office. Guidelines for the use of ILO international classification of radiographs of pneumoconioses. Rev ed. Geneva: ILO, 1980. (Occupational Safety and Health series No 22.)

7 Sullivan J, Parker M, Carson SB. Tissue cobalt content in "beer drinkers' myocardiopathy." J Lab Clin Med 1968;71:893-6.

8 Morin Y, Tetu A, Mercier G. Cobalt cardiomyopathy: clinical aspects. Br Heart $J 1971 ; 33$, suppl: 175-8.

9 Bonenfant JL, Miller G, Roy PE. Quebec beer drinkers' cardiomyopathy: pathologic studies. Can Med Assoc J 1967; 97:910-31.

10 Morin Y, Daniel P. Quebec beer drinker's cardiomyopathy: etiologic consideration. Can Med Assoc J 1967;97:926-8.

11 Taylor DM. The absorption of cobalt from the gastrointestinal tract of the rat. Phys Med Biol 1962;6:445-51.

12 Webb M. The biological action of cobalt and other metals III. Chelation of cations by dihydrolipoic acid. Biochemica, Biophysica Acta 1962;65:47-65.

13 Liquier-Milward J. Evidence of a complex compound of cobalt with a purine base (Adenine). Nature 1951;167:1068-9.

14 Wiberg GS, Monro IC, Morrison AB. Effect of cobalt ions on myocardial metabolism. Canadian Journal of Biochemistry 1967;45:1219-23.

15 Rona G. Experimental aspects of cobalt cardiomyopathy. $\mathrm{Br}$ Heart $J$ 1971;33:171-4.

16 Rodeheffer RJ, Gerstenblith G, Becker LC, Fleg JL, Weisfeldt ML, Lakatta EG. Exercise cardiac output is maintained with advancing age in healthy human subjects: cardiac dilatation and increased stroke volume compensate for a diminished heart rate. Circulation 1984;69:203-13.

17 Hartz AJ, Anderson AJ, Brooks HL, et al. The association of 
smoking with cardiomyopathy. $N$ Engl J Med 1984;311:1201-6.

18 Ellis JH, Kirch D, Steele PP. Right ventricular ejection fraction in severe chronic airway obstruction. Chest 1977;71:281-2.

19 Brent BN, Mahler D, Berger HJ, Matthay RA, Pytlik L, Zaret BL. Physiologic correlates of right ventricular ejection fraction in chronic obstructive pulmonary disease: a combined radionuclide and hemodynamic study. Am J Cardiol 1982;50:255-62.

20 Cohen M, Horowitz SF, Machac J, Mindich BP, Fuster V. Response of the right ventricle to exercise in isolated mitral stenosis. Am J Cardiol 1985;55:1054-8.

21 Bech AO, Kipling MD, Heather JC. Hard metal disease. Br J Ind
Med 1962;19:239-52.

22 Strashun A, Goldsmith SJ, Horowitz SF. Serial assessment of adriamycin cardiomyopathy with the scintillation probe. In: Raynand C, ed. Proceedings of the third world congress of Nuclear Medicine and Biology, Paris, 1982.

23 Chew C, Ziady GM, Raphael MJ, Oakley CM. The functional defect in amyloid heart disease: the "stiff heart" syndrome. Am J Cardiol 1975;36:438-44.

24 Sandusky GE, Crawford MP, Roberts ED. Experimental cobalt cardiomyopathy in the dog: a model for cardiomyopathy in dogs and man. Toxicol Appl Pharmacol 1981;60:263-8.

\section{Vancouver style}

All manuscripts submitted to the $\mathrm{Br} J$ Ind Med should conform to the uniform requirements for manuscripts submitted to biomedical journals (known as the Vancouver style)

The $\mathrm{Br} J$ Ind Med, together with many other international biomedical journals, has agreed to accept articles prepared in accordance with the Vancouver style. The style (described in full in $\mathrm{Br}$ Med J, 24 February 1979, p 532) is intended to standardise requirements for authors.

References should be numbered consecutively in the order in which they are first mentioned in the text by Arabic numerals above the line on each occasion the reference is cited (Manson ${ }^{1}$ confirmed other reports ${ }^{2-5} \ldots$.). In future references to papers submitted to the $\mathrm{Br} J$ Ind Med should include: the names of all authors if there are six or less or, if there are more, the first three followed by et al; the title of journal articles or book chapters; the titles of journals abbreviated according to the style of Index Medicus; and the first and final page numbers of the article or chapter.

Examples of common forms of references are:

1 International Steering Committee of Medical Editors. Uniform requirements for manuscripts submitted to biomedical journals. Br Med J 1979;1:532-5.

2 Soter NA, Wasserman SI, Austen KF. Cold urticaria: release into the circulation of histamine and eosino-phil chemotactic factor of anaphylaxis during cold challenge. $N \mathrm{Engl}$ J Med 1976;294:687-90.

3 Weinstein L, Swartz MN. Pathogenic properties of invading micro-organisms. In: Sodeman WA Jr, Sodeman WA, eds. Pathologic physiology: mechanisms of disease. Philadelphia: W B Saunders, 1974:457-72. 